\title{
MAGEA12 Positive
}

National Cancer Institute

\section{Source}

National Cancer Institute. MAGEA12 Positive. NCI Thesaurus. Code C150681.

An indication that MAGEA12 expression has been detected in a sample. 